\title{
The 2019 International Day of Light in Spain
}

\section{El Día Internacional de la Luz en España en 2019}

\author{
María J. Yzuel1,s,r, Ignacio Moreno2,s, ${ }_{,}, \mathrm{r}$, María L. Calvo3,s, $\mathrm{r}$ \\ 1. Departamento de Física, Universitat Autònoma de Barcelona, Spain \\ 2. Departamento de Ciencia de Materiales, Óptica y Tecnología Electrónica, Universidad Miguel Hernández \\ de Elche, 03202 Elche, Spain \\ 3. Departamento de Óptica, Universidad Complutense de Madrid, Spain \\ $\left.{ }_{(*}\right)$ E-mail: i.moreno@umh.es \\ S: miembro de SEDOPTICA / SEDOPTICA member
}

Received: 05/12/2019 Accepted: 08/12/2019

DOI: 10.7149/OPA.52.4.xiii

\begin{abstract}
:
This paper reports on the main activities related to the International Day of Light (IDL) in Spain throughout 2019. After the success in 2018, the Spanish Committee for the IDL continued the promotion and dissemination of related activities in optics, photonics and the world of light science, and attract students for science and engineering degrees. In particular, a new flagship IDL event in Spain was organized this year at the University of Santiago de Compostela. Moreover, many other interesting activities have been reported. This paper reviews and summarizes these activities related to this international educational project, intended to make our society aware of the importance of light science and light-based technologies.
\end{abstract}

Key words: International Day of Light, Outreach, Education, Spain

RESUMEN: Este artículo recoge las principales actividades relacionadas con el Día Internacional de la Luz (DIL) en España a lo largo de 2019. Después del éxito en 2018, el Comité Español del DIL continuó la promoción y difusión de actividades relacionadas en óptica, la fotónica y la ciencia de la luz, y de esta forma atraer estudiantes hacia los estudios de ciencias e ingeniería. En particular, este año se organizó un nuevo acto central del DIL en España en la Universidad de Santiago de Compostela. Además, se han desarrollado otras muchas actividades interesantes. Este documento revisa y resume estas actividades relacionadas con este proyecto educativo internacional, destinado a concienciar a nuestra sociedad sobre la importancia de la ciencia de la luz y las tecnologías basadas en la luz.

Palabras clave: Día Internacional de la Luz, Divulgación, Educación, España

\section{REFERENCES AND LINKS / REFERENCIAS Y ENLACES}

[1] I. Moreno, M. J. Yzuel, M. L. Calvo, "The first International Day of Light in Spain", Proc. SPIE 10741, 1074109 (2019).

[2] Official website in Spain for the IDL: http://www.diadelaluz.es

[3] Official international website for the IDL: http://www.lightday.org

[4] J. Dudley, J. Rivero González, “Día Internacional de la Luz, 16 de mayo: una celebración anual”, Revista Española de Física 32(2), 43-47 (2018).

[5] D. Curticapean, O. Vauderwange, B. Heitz, "International Day of Light (IDL): a new forum for interdisciplinary learning concepts in optics and photonics", Proc. SPIE 11143, 1114334 (2019).

[6] Recording of the conferences of the Central IDL Event in Spain, Santiago de Compostela: LINK

$\Upsilon$ Note about the authors: María J. Yzuel is President of the Spanish Committee of the IDL, and Ignacio Moreno and María L. Calvo are Vice-presidents of the Committee [2]. 
[7] Official website of COSCE - Confederación de Sociedades Científicas de España:

https://www.cosce.org/

[8] UNED video devoted to 2019 IDL: https://canal.uned.es/video/5d1dfc44a3eeb07c5a8b4567

[9] UNED radio emission devoted to 2019 IDL: https://canal.uned.es/video/5ae034c5b1111f2f2a8b456a https://www.youtube.com/watch?v=Aea4KrKNxdY

[10] Misión ALBA website: www.misionalba.es

[11] SPIE Annual IDL Photo Contest website: https://spie.org/about-spie/international-day-of-light/spieidl-photo-contest

\section{Introduction}

After the great success of the first International Day of Light (IDL) in Spain in 2108 [1], the Spanish Committee for the IDL considered the importance of continuing their work to promote and disseminate the related activities. For that purpose, the specific website [2] and the related social media have remained active and it recalls all the information of events in Spain.

Many different activities have been developed this year in different locations in Spain, including a main flagship central event that took place this year at the well-known city of pilgrims, Santiago de Compostela. The aim of this paper is to describe and review all these activities in Spain related to the IDL. According to the goals of the IDL proclamation [3], these activities are intended to enable global appreciation of the central role that light and light-based technologies play in the lives of the citizens of the world in areas of science, technology, culture, education, and sustainable development, embedded technologies in our daily life. Also, they were intended to emphasize the importance of basic research in the fundamental science of light, the need for investment in light-based technology to develop new applications and improvements, and the necessity to promote careers in science and engineering in these fields $[4,5]$.

To accomplish these goals, the Spanish Committee for the IDL counted with the support of different national and international sponsors and collaborators, listed in Fig. 1.

After this brief introduction, the paper is organized as follows: in Section 2 the main flagship event of the IDL in Spain organized at Universidade de Santiago de Compostela (USC) is described; then, section 3 is devoted to other relevant activities related to the IDL that were organized in 2019; finally, the conclusions and the perspectives for 2020 will be discussed in Section 4 .

\section{The Central IDL Event in Spain at Santiago de Compostela}

The University of Santiago de Compostela (USC) held this year the IDL Central Event in Spain. It took place in May 15th, at the historical building Hostal de los Reyes Católicos (founded in the 15th century by the Monarchs it was a former hostel for pilgrims). The event was organized by Prof. María Teresa Flores Arias, President of the Local Organizing Committee, together with Prof. Carmen Bao Varela and Prof. Justo Arines Piferrer, all from the Department of Applied Physics of USC, and by María Aymerich, President of the Student Chapter in Santiago.

The opening ceremony included the participation of Carmen Pomar, Conselleira de Educación, Xunta de Galicia, Prof. Vicente Pérez, USC Vice-chancellor for Research and Innovation, Prof. María L. Calvo, Vice president of the Spanish Committee of IDL, Prof. Humberto Michinel, President of the EOS - European Optical Society and Secretary General of the International Commission for Optics (ICO) and Prof. María S. Millan, Vice president of SEDOPTICA - Spanish Society of Optics.

The event included four different conferences by four Spanish experts in optics and photonics, as well as an exhibition and activities for students. These conferences were:

- "Technologies to see better", by Prof. Pablo Artal, University of Murcia;

- "Light, darkness and biological clocks", by Prof. María de los Ángeles Rol, University of Murcia;

- "Extreme optics: an excursion through the limits of laser light", by Prof. Luis Plaja, University of Salamanca

- $\quad$ "Let the light be with you", by Mercedes Angulo, University Complutense of Madrid.

All these conferences, as well as the opening ceremony, were recorded by the USC TV and they are now freely available through the Spanish IDL website [6]. 
The audience was about 250 participants, mainly secondary school students interested in STEM (Science, Technology, Engineering and Mathematics). Students of the Physics degree of USC participated as monitors for the experiments shown to younger students.

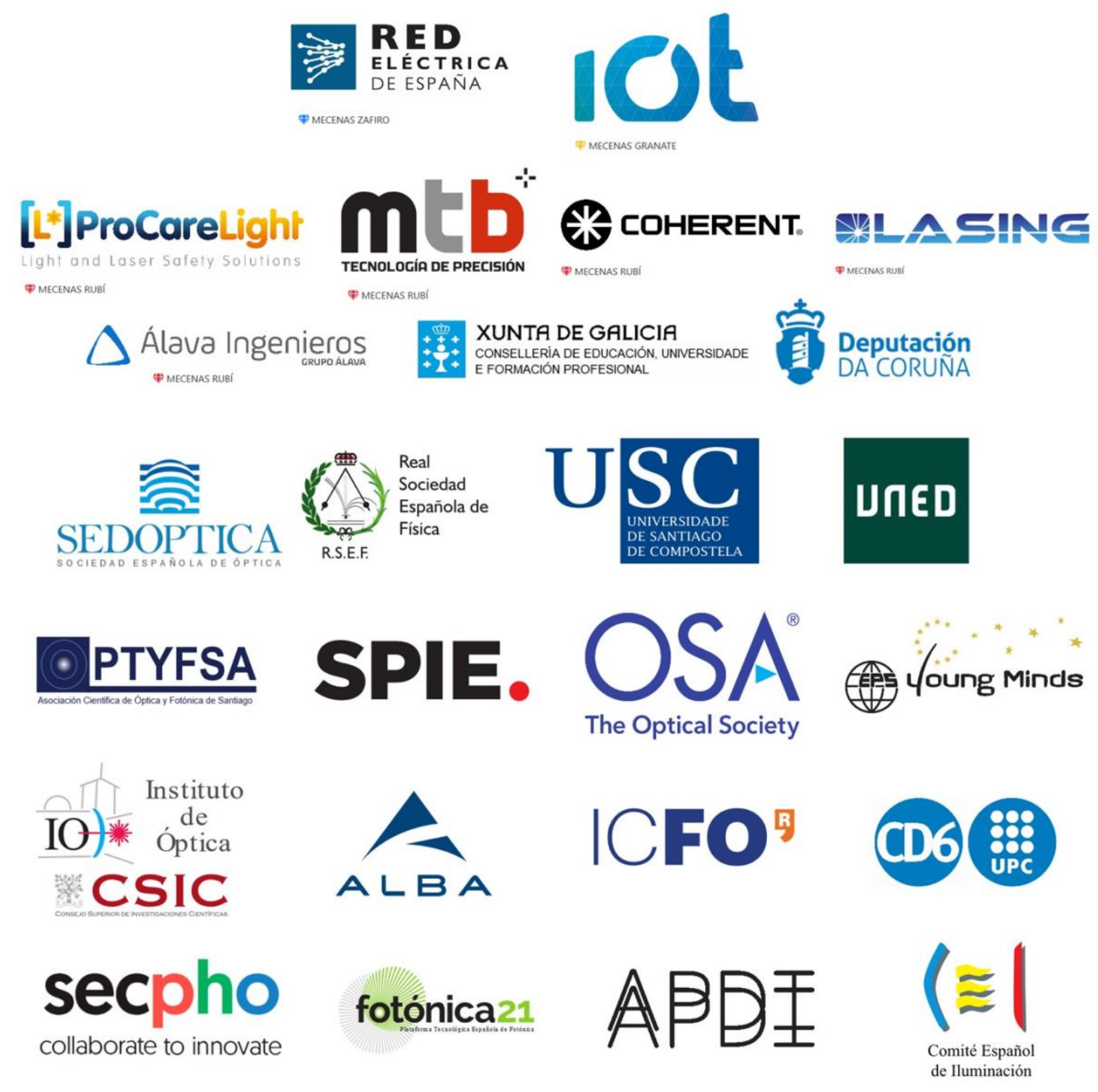

Fig.1. Sponsors and collaborators of the 2019 IDL in Spain. 


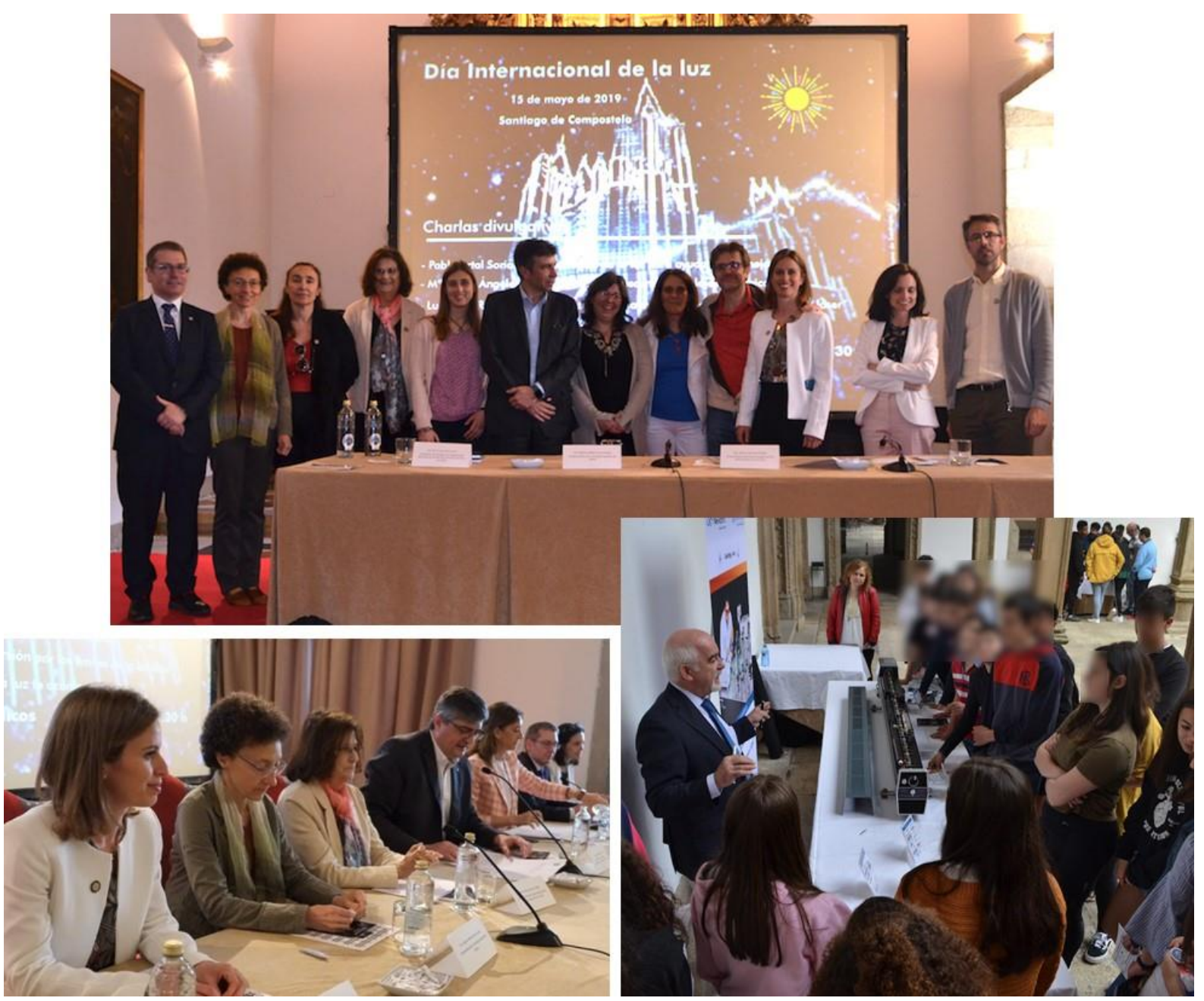

Fig.2. Top: Organizers, speakers and authorities at the 2019 IDL Central Event in Santiago de Compostela. Bottom left: opening ceremony; Bottom right, Valentín Guadaño, from the company LASING, showing the first He-Ne laser installed in Spain to young students during the exhibition.

\section{Other relevant IDL related events}

This section reviews other IDL related events that took place the year 2019 in Spain. These are selected from a large number of different events that have been included in the official website [2].

\section{3.a. Reproduction of the Fizeau experiment to measure the speed of light at Santander}

The year 2019 happened to be the 200 anniversaries of the birth of the French scientist Hyppolite Fizeau, and the 170 anniversaries of his famous experiment to measure the speed of light. For this reason, a group of 16 students of the degree of Physics of the University of Cantabria, supervised by the professors Fernando Moreno, Pedro Valle, and José Ma Saiz, reproduced this historical experiment. For that purpose, they used a laser located at the Oceanographic Spanish Institute (IEO) directed to the top of the so-called Peña Cabarga, where a reflector was located, thus light travelling twice a distance of $9.4 \mathrm{kms}$ over Santander bay. The experiment was reported by the local press in Cantabria (Fig. 4(a)).

\section{3.b. The 2019 COSCE Workshop of Societies and the UNED TV and radio emissions}

COSCE is the Confederation of Scientific Societies of Spain [7]. Its goal is to contribute to the scientific and technological development in Spain and to be a qualified and unified representative of the global scientific community to address knowledge of the world of science to the society and to the political media of our country. Currently, it joins 82 Spanish scientific societies, including the two Spanish scientific societies participating in the Spanish Committee for the IDL: SEDOPTICA - the Spanish Society of Optics, and RSEF the Royal Spanish Society of Physics.

Every year COSCE organizes the Workshop of Societies, devoted to a specific subject. This year, COSCE, devoted its 2019 annual workshop to the Day of Light, in collaboration with FACME, the Federation of 
Spanish Medical Scientific Societies. This event was held on June 6th, 2019 at the Historical Library of the University Complutense of Madrid. It consisted in 8 conferences by different experts, that covered different aspects of the interaction of the light with the different sciences.

Taking profit of the event UNED, the Spanish National Distance Education University (Open University), recorded a report of this event. This report has been broadcast in "La 2 de TVE", the second channel of the Spanish national public TV, with a high number of viewers. This video (in Spanish) is based on interviews to different participants and include, among others, the speakers at the workshop, as well as the President of the Spanish Committee of the International Day of Light. It can be viewed at the UNED TV channel [8]. It complements another UNED emission that was recorded for emission on Radio Nacional de España (Spanish National Radio), that was broadcast on May 12th, and can be listened at UNED channel and YouTube [9].

\section{3.c. Exhibition: “GRANAglyphs. A stereoscopic vision of Granada”}

The Optics Department of the University of Granada and the Science Museum (Parque de las Ciencias. Granada) organized this exhibition, being the curators Prof. José Juan Castro and Prof. Enrique Hita, associate professor and emeritus professor of this department, respectively. The IDL Spanish Committee has also collaborated on this event.

The word "GRANAglyph" is the result of mixing the words Granada and Anaglyph, in such a way that a GRANAglyph is an anaglyph of the Granada city. The exhibition: "GRANAglyphs. A stereoscopic vision of Granada", was located for several months in the Foucault Pendulum Building in the Parque de las Ciencias. The exhibition shows results from a teaching innovation project developed at the University of Granada, based on the collaborative work between students from different degrees (Architecture, Optics and Optometry, History of Art, Laws) using as the main resources the historic-artistic heritage of the Granada city and the stereoscopic photography.
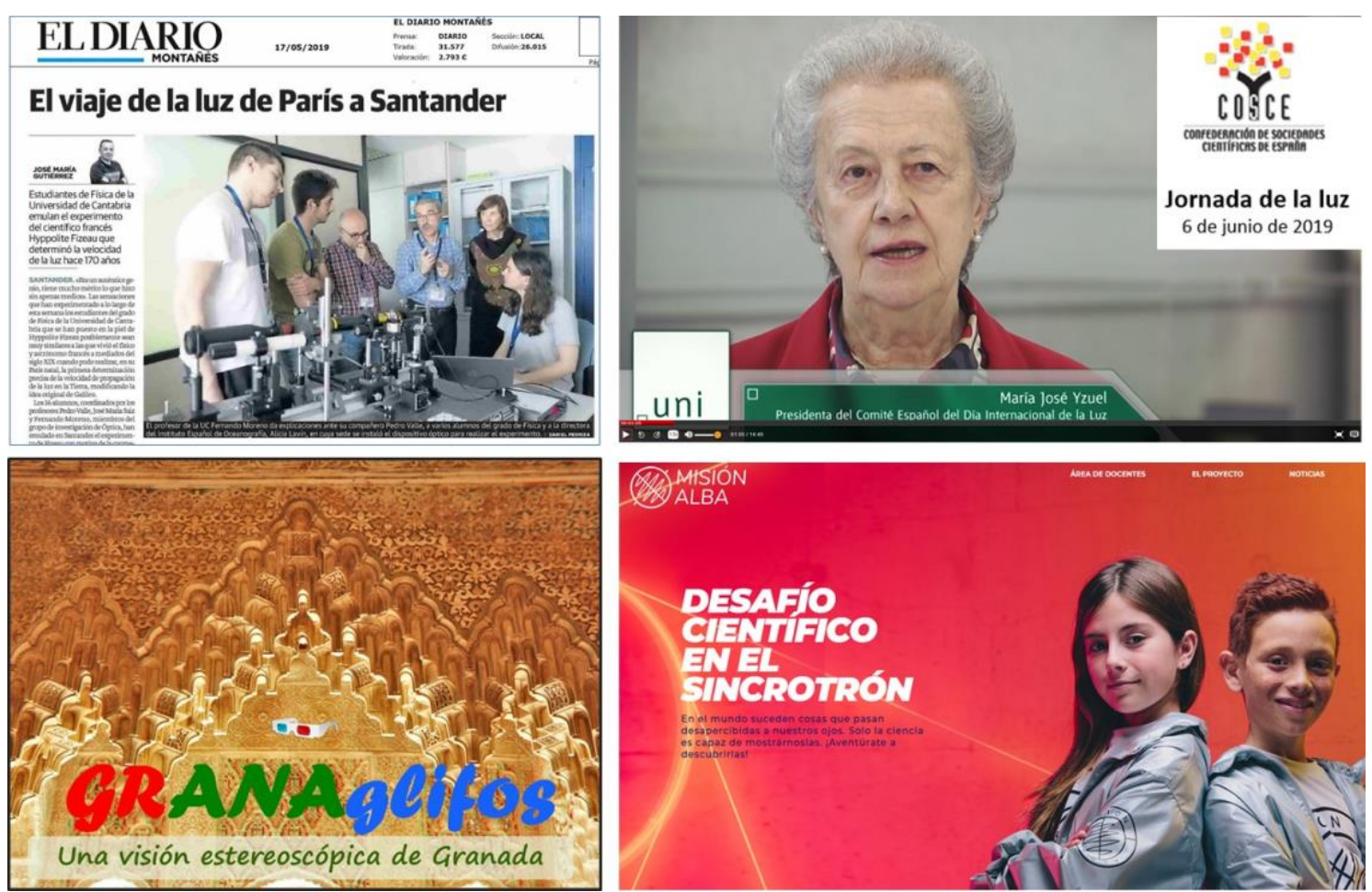

Fig.3. Top left: Report on the journal "El Diario Montañés”, Cantabria; Top right: María J. Yzuel, President of the Spanish Committee for IDL in a photogram of the report broadcast in the Spanish TV channel "La 2 de TVE” recorded by UNED; Bottom left: Promotional image of the GRANAGLIFOS exhibition; Bottom right: picture of the 'Misión ALBA' program.

Notice that the most important monuments of Granada were declared World Heritage Site by the UNESCO: Alhambra and Generalife in 1984 and Albaycin in 1994. Some anaglyphs are done in these monuments. Furthermore, a selection of more than 200 stereoscopic photographs (anaglyphs) were shown, being Prof. José Juan Castro the author. Some anaglyphs of the Parque de las Ciencias (Park of Sciences) were also 
included. In addition, a sample of anaglyphs of the Jódar city (Jaén, Spain) were shown, in a project currently developed by the author due to the celebration of the 100 anniversary of the declaration of Jodar as a City.

Visitors of the exhibition could perceive the stereo images of Granada with red-blue glasses, but also they will be able to make their own 3D glasses using a template and a pair of red-blue filters, afterward enjoying GRANAgliphs by downloading the free access book about the project.

\section{3.d. 'Misión ALBA' project for primary school students}

Misión ALBA is an educational project, launched for the first time during the academic year 2018-2019, by the ALBA Synchrotron. It hosts four virtual laboratories at their website [10]. Under the motto of "making visible the invisible", in each phase scientists and engineers of the ALBA Synchrotron challenge the participating teams to a scientific "mystery" that they will investigate doing experiments in the classroom.

Following the instructions of the ALBA Synchrotron experts, the students must find out the scientific answer and, if they succeed, they will be able to proceed to the next phase until they reach the final goal of the "mission". One of the labs is specially focused on light and its properties. The first edition finished last May 2019 and counted with the participation of more than 7,000 students coming from 170 schools all around Spain. The second edition is now open again for 2019-2020 years.

\section{3.e. ORIGAMI Project at the Archaeological Site of the Dolmens of the Antequera city}

The Origami Project was designed by Victor Marín and his company Brain and Glasses, to be carried out in the Archaeological Site of the Dolmens of Antequera (Málaga), a site declared by UNESCO World Heritage Site since 2016. The Spanish DIL Committee supported the project and was represented in its celebration on July 14 th 2019 by Prof. Enrique Hita.

In this project light was used to show the trajectories that mark the exceptionality in the singular orientation of the Dolmens of Antequera, that were imagined by our ancestors about 6,000 years ago. Dr. Juan Diego Ania, Director of the Institute of Optics (CSIC), and member of the Spanish Committee for the IDL, was the scientific advisor for the project, specifically for the use of lasers.
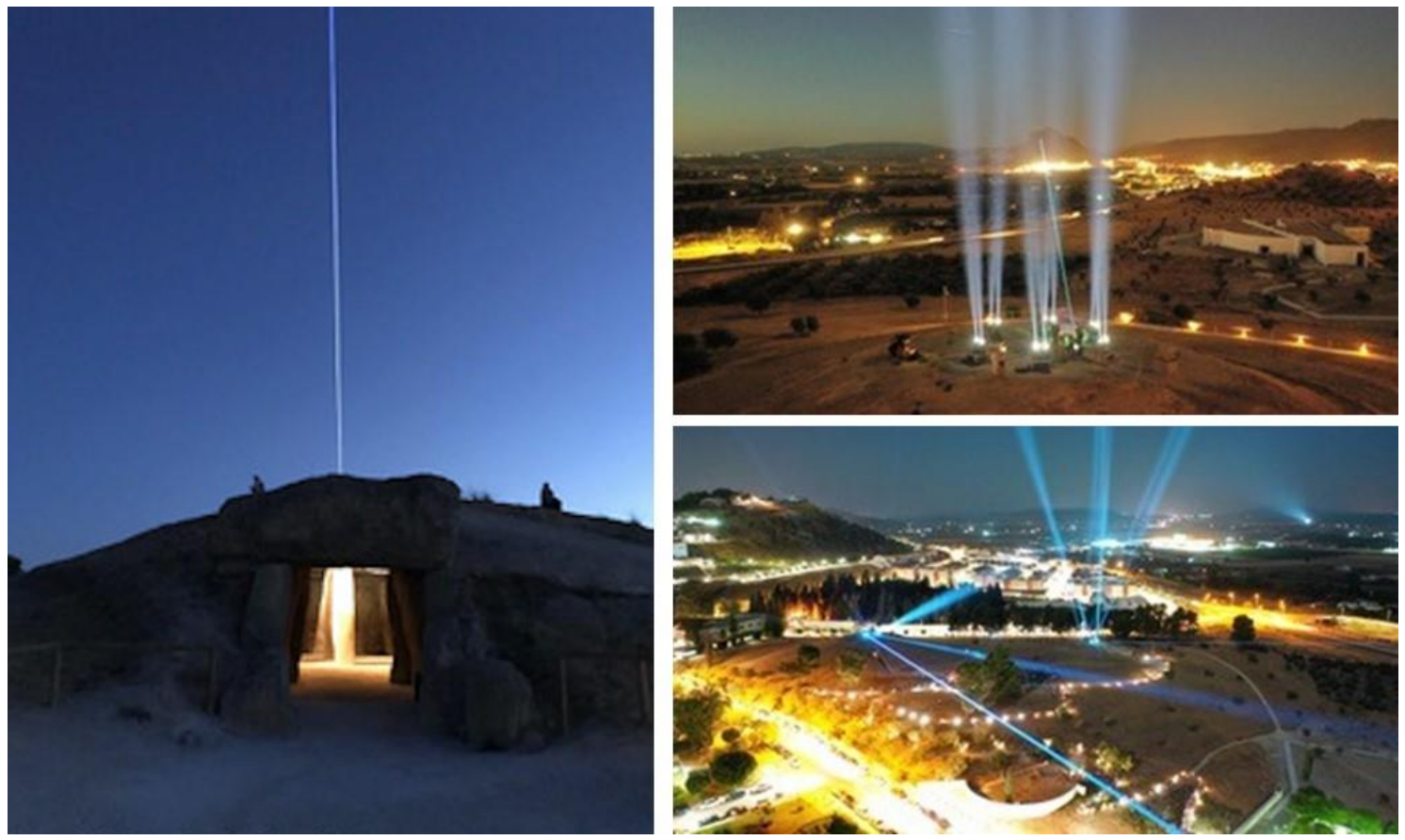

Fig.4. Left: Laser over Dolmen de Menga; Top right: Structure built to create light patterns and spatially locate each Dolmen; Bottom right: Top view of the light structures indicating the positions and orientations of the Dolmens.

\section{3.f. The PHOTON awards}

For the second year, the Institute of Optics "Daza de Valdés" (IO-CISC) from the National Research Council (CSIC) delivered the Photon Awards. This initiative, in collaboration with SEDOPTICA and secpho, aims to recognize the work of communication, dissemination and approach to public opinion of the scientific, technological and social impact of research in optics and photonics and, on the other, to promote and 
encourage the teaching of science and research and, in particular, optics and photonics to elementary and high school students (Fig. 5).

The Emitted Photon first prize was awarded to the scientific journalist Laura Chaparro, for her report entitled "The new era of invisible materials". The second prize was awarded to Susana Eva Martínez, for her script of the scientific play "Engraving in the retina". In the Absorbed Photon category, the activity "Cheating on sight", by IES Diego Velázquez, from Torrelodones (Madrid), presented by professors Pablo Cassinello and Cristina Somolinos, which focused on experiments on the phenomena of light.

\section{3.g. ... and many other activities and news}

Many other quite relevant activities and events have been done at many cities in Spain. All the information can be found in the Spanish website for IDL [2], where numerous sources of information can be found as well.

Very recently we were very glad that two Spanish photographers were awarded with prizes at the SPIE 2019 IDL Annual Photo Contest [11]: the third prize was awarded to Julio Castro Pardo from La Coruña, Spain for his image 'A Dream Come True', while the Technology Prize was given to Sergio Ruiz from Barcelona, for his image 'ALBA Synchrotron' (Fig. 5).
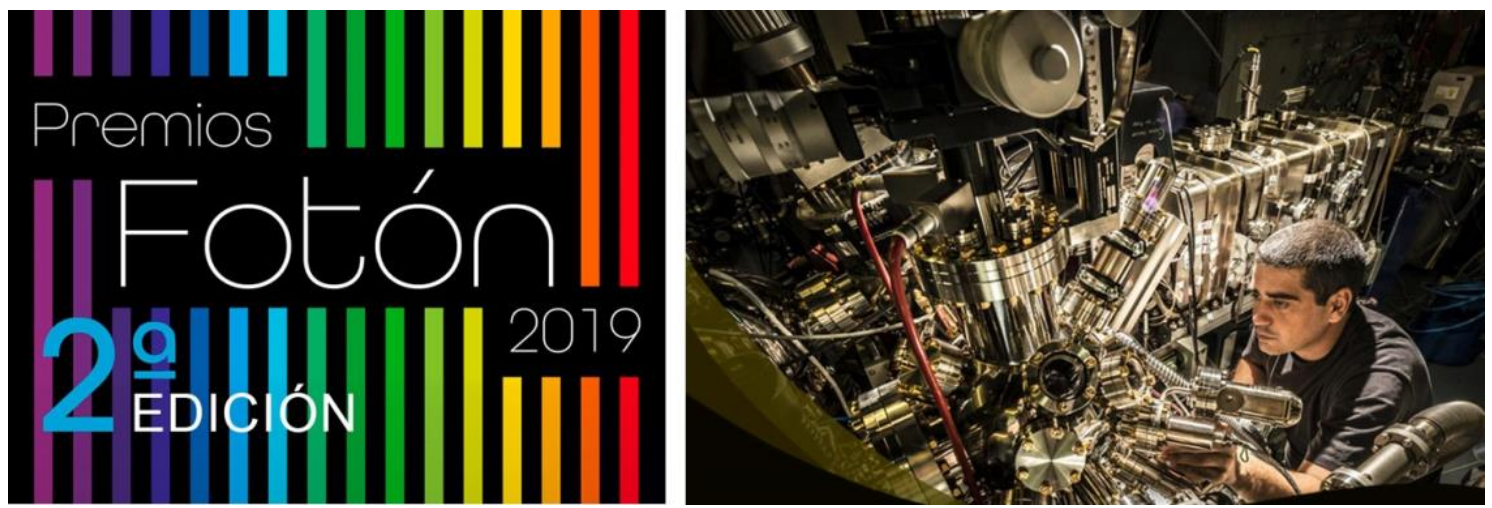

Fig.5. Left: Flyer of the PHOTON Awards by IO-CSIC; Right: image 'ALBA Synchrotron by Sergio Ruiz from Barcelona, who won the Technology Prize of the 2019 IDL SPIE Photo Contest.

\section{What's next? The 2020 IDL in Terrassa}

As a conclusion of this selected collection of activities, we strongly believe the IDL is a firm pillar to promote the science and technology of light among the Spanish audience, in all ages and social areas. A remarkable increasing number of activities is being developed each year, with a high impact rate. Throughout 2019, more than 70 different activities have been announced and linked at the Spanish website [2].

The Spanish Committee for the IDL is being involved in the coordination of the 2020 IDL. In fact, the flagship Central IDL Event in Spain is already designated to be held in the city of Terrassa, organized by the Faculty of Optics and Optometry of Terrassa (FOOT). The organizers of this event want to give special emphasis to Light, Vision and Visual Health, taking advantage of the fact that the year 2020 coincides with the nomenclature $20 / 20$, which is commonly used to designate normal visual acuity in common eye examinations.

A Local Committee with representatives of FOOT and its Board of Trustees, the Universitat Politècnica de Catalunya (UPC), the City Hall of Terrassa and the Spanish Optical Society (SEDOPTICA) has started to work on the design of the activity program. Faculty members of the F00T, Prof. María Sagrario Millán, Dr. Genis Cardona will participate in this Committee, along with Prof. Elisabet Pérez-Cabré, who will act as a Chair. 


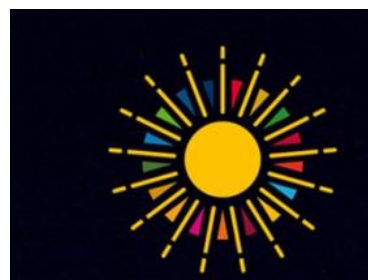

Día Internacional

de la Luz

\section{6 de Mayo}
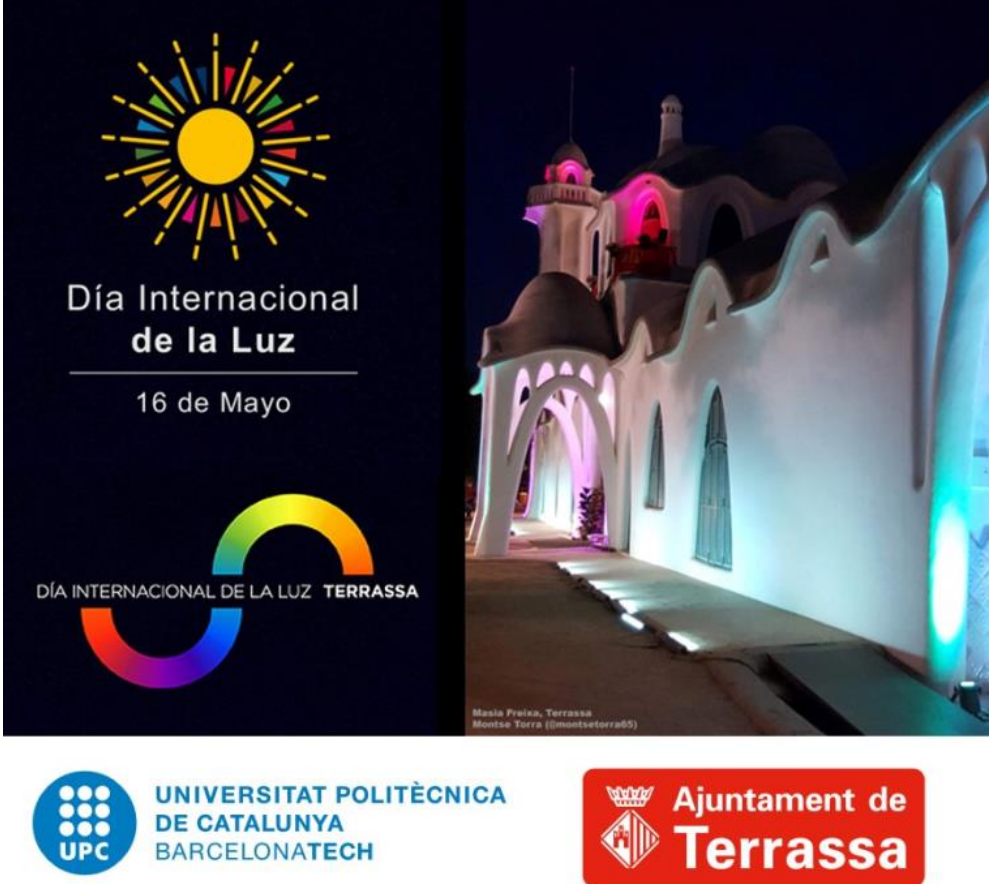

Fig.6. Announcement of the 2020 IDL flagship central event in Terrassa.

The celebration of this Central Event will run from Friday, 15th May to Saturday, 16th May 2020. In keeping with the spirit of the IDL, the Local Organizing Committee is programming a set of activities related to light to show its transversal impact (in science, technology, health, education, entertainment, sustainability, society, and so on) and to reach a broad and heterogeneous audience.

\section{Acknowledgements}

The authors would like to thank all the members of the Spanish Committee for the IDL, all the sponsors and organizations collaborating, and all the participants in the different IDL activities in Spain along the year 2019. 